\title{
Social rules govern vocal competition in the barn owl
}

\author{
Amélie N. Dreiss ${ }^{a, *}$, Charlène A. Ruppli ${ }^{a}$, Christof Faller ${ }^{b}$, Alexandre Roulin ${ }^{a}$ \\ a Department of Ecology and Evolution, University of Lausanne, Lausanne, Switzerland \\ ${ }^{\mathrm{b}}$ Audiovisual Communications Laboratory, Ecole Polytechnique Fédérale de Lausanne (EPFL), Lausanne, Switzerland
}

\section{A R T I C L E I N F O}

\section{Article history:}

Received 28 April 2014

Initial acceptance 26 June 2014

Final acceptance 19 November 2014

Available online 5 February 2015

MS. number: 14-00349R

\section{Keywords:}

communication

competition

conflict dynamics

negotiation

sibling

signalling

social rules

turn taking

vocal rules
To resolve the share of limited resources, animals often compete through exchange of signals about their relative motivation to compete. When two competitors are similarly motivated, the resolution of conflicts may be achieved in the course of an interactive process. In barn owls, Tyto alba, in which siblings vocally compete during the prolonged absence of parents over access to the next delivered food item, we investigated what governs the decision to leave or enter a contest, and at which level. Siblings alternated periods during which one of the two individuals vocalized more than the other. Individuals followed turn-taking rules to interrupt each other and momentarily dominate the vocal competition. These social rules were weakly sensitive to hunger level and age hierarchy. Hence, the investment in a conflict is determined not only by need and resource-holding potential, but also by social interactions. The use of turn-taking rules governing individual vocal investment has rarely been shown in a competitive context. We hypothesized that these rules would allow individuals to remain alert to one another's motivation while maintaining the cost of vocalizing at the lowest level.

( 2015 The Association for the Study of Animal Behaviour. Published by Elsevier Ltd.
Natural selection has favoured the evolution of behaviours and weapons to outcompete conspecifics, or of communication systems to resolve the share of resources (Maynard Smith, 1982; Parker, 1974). The term 'negotiation' is usually used for humans who bargain for resources and the process typically ends with a decision about which part of the resource each participant obtains (Nash, 1950). Evolutionary ecologists also use this concept to define situations in which animals communicate to reach an agreement about how a resource is shared or how to invest in a collaborative task (Johnstone \& Hinde, 2006; Johnstone \& Roulin, 2003; McNamara, Gasson, \& Houston, 1999; Patricelli, Krakauer, \& McElreath, 2011; Sirot, 2012). An individual that presents conspicuous ornaments or signals at higher levels than its opponents (e.g. produces louder begging calls in nestling birds) usually gains easier access to these limited resources (Godfray, 1991; Kilner, Noble, \& Davies, 1999), but, for transient signals, this average signal level can vary over short periods of time, independently of variation in need or condition (Briffa, Elwood, \& Dick, 1998; Greenfield, Tourtellot, \& Snedden, 1997). The contest outcome is then the result of an

\footnotetext{
* Correspondence: A. N. Dreiss, Department of Ecology and Evolution, University of Lausanne, 1015 Lausanne, Switzerland.

E-mail address: amelie.n.dreiss@gmail.com (A. N. Dreiss).
}

interactive process settled during repeated interactions (Briffa et al., 1998; Enquist \& Leimar, 1983; Enquist, Leimar, Ljungberg, Mallner, \& Segerdahl, 1990; Payne \& Pagel, 1996).

These variations in signal level during competitive interactions raise the possibility that animals assess the temporal dynamics of signal production and not only the absolute signalling level of conspecifics to adjust their behaviour (Patricelli, Uy, Walsh, \& Borgia, 2002). Game theory has dominated the way evolutionary biologists envisage social interactions (Dobler \& Kolliker, 2009; McNamara et al., 1999), and the dynamic process leading animals to behave in a certain way has hardly been investigated empirically (Briffa et al., 1998; Van Dyk, Taylor, \& Evans, 2007). Much remains to be done to pinpoint the social factors that induce an individual to increase or decrease investment in signalling over short periods of time in the course of competitive interactions. Studying the shortterm temporal dynamics of signalling should provide key elements in our understanding of social decision making.

In the present study, we investigated in barn owl, Tyto alba, nestlings what governs the investment in a sibling vocal contest, which will ultimately determine which individual obtains the next food item delivered by a parent. While parents are hunting, nestlings vocally compete and the most vocal nestling in the absence of parents has a higher chance of being fed when a parent returns than its less voluble siblings (Dreiss, Lahlah, \& Roulin, 2010; Roulin, 
2002). Each nestling invests in a sib-sib vocal contest according to its hunger level, hungrier individuals producing longer calls at higher rates on average (Johnstone \& Roulin, 2003, Roulin, 2002; Ruppli, Dreiss, \& Roulin, 2013), but also according to its siblings' vocalizations, withdrawing when its siblings produce longer calls at higher rates (Roulin, 2002; Ruppli et al., 2013). Such vocal competition during this so-called 'sibling negotiation' has been suggested in several taxa (Bulmer, Celis, \& Gil, 2008; Madden, Kunc, English, Manser, \& Clutton-Brock, 2009) and would limit the cost of food competition (Johnstone \& Roulin, 2003), because individuals invest in competition according to their chance of winning.

As in most competition, the aim of each nestling should be to impose itself in the contest, hence to produce longer calls and to be 'vocally dominant' (i.e. to produce more calls) than its siblings, since it would be more likely to obtain the prey item and gain direct fitness benefits (Dreiss, Lahlah, et al., 2010). In the meantime, individuals should obtain information from competing siblings. Indeed, it is pointless to compete for a predictable outcome (i.e. when the between-siblings asymmetry in food need is very high, the hungriest individual is more likely to win the contest), especially because the prey is indivisible and competitors are kin, sharing indirect genetic benefits (Johnstone \& Roulin, 2003). We predicted that, at each time point, individuals should minimize the cost of vocal competition by producing the lowest level of signal that allows them to obtain the prey, hence maximizing signal efficiency. Individuals are hence expected to apportion their investment in the competition dynamically and participants are predicted to be vigilant to their siblings (Dreiss, Calcagno, et al., 2013), as shown by their tendency to avoid calling simultaneously (Dreiss, Ruppli, Oberli, et al., 2013). Because individuals should assess the motivation level of competitors, they are predicted to use acoustic cues to allow one another to alternate (Hauser \& Fowler, 1992; Versace, Endress, \& Hauser, 2008) or even to incite competitors to resume calling in order to obtain information about sibling motivation. Because vocally dominant individuals are likely to be fed first, but vocalizing is likely to be costly (Bühler \& Epple, 1980), nestlings should endeavour to optimize their investment in competition by producing signals just intense enough to dominate the current competitive interaction. We hence predicted that nestling barn owls should escalate signal production until their siblings stop calling, and from this moment they should reduce their vocal investment until they are challenged again by siblings.

To test these hypotheses, we examined the temporal dynamics of vocal exchanges and investigated what induces an individual to momentarily increase or decrease investment in a vocal contest, i.e. the variation in call features over time, and finally to enter and abandon a vocal competition, i.e. the turn-taking rules. Our aim was to understand how animals dynamically modulate signals to one another in relation to short-term social interactions. We thus investigated how animals presenting similar levels of motivation to compete decide to invest in signalling at each time point of a contest in relation to the behaviour of their opponent. Using an automatic analysis of acoustic sonograms, we studied isolated pairs of siblings, alternately food-satiated or food-deprived, in random order, and comprising an older (the 'senior') and a younger individual (the 'junior'). The two individuals had the same food treatment in order to reduce the level of asymmetry in food need between them as much as possible. This design should allow us to study social turn-taking rules, which is difficult to do if the asymmetry in food need between two siblings is pronounced, since in that case only one individual is usually vocalizing (Roulin, 2002). To subsequently test the decision rules found in natural exchanges, we broadcast natural sequences of calls produced by a single nestling and analysed the individual response. Finally, to disentangle which acoustic factors induce a nestling to enter a vocal contest, we compiled playbacks of barn owl calls for which duration and production rate varied.

\section{METHODS}

We studied a wild population of barn owls breeding in nestboxes $(62 \times 56 \mathrm{~cm}$ and $37 \mathrm{~cm}$ high) located on barn walls in Switzerland $\left(46^{\circ} 4^{\prime} \mathrm{N}, 6^{\circ} 5^{\prime} \mathrm{E}\right)$. In 2008 clutches of four to eight eggs were laid between 23 April and 6 August, in 2009 2-10 eggs between 12 May and 16 August and in 2011 four to nine eggs between 14 March and 22 July. Eggs are laid on average every 2.5 days and incubation starts after the first egg has been laid generating a pronounced age hierarchy among siblings. Throughout the night each barn owl nestling produces between 1000 and 5000 hissing calls towards its siblings to compete for priority in access to the next indivisible mouse delivered by a parent (Roulin, 2002).

\section{Recording Vocal Interactions Between Pairs of Siblings}

In 2008, when nestlings were 22-45 days old (mean $\pm \mathrm{SE}$ : $35 \pm 5$ ), we brought 156 nestlings from 41 nests to the university; we always left one or more nestlings in the natural nest to make sure that parents did not abandon their brood. In the laboratory, we randomly matched siblings in 78 pairs and housed each pair in a soundproof wooden nestbox, identical in size to the ones in which they were reared under natural conditions. The box was divided in half by a thin wooden wall pierced with five holes at the top, so that siblings could hear each other without visually or physically interacting. The senior individual was 5 days older than its junior sibling on average (range in age difference 1-15 days). We examined the effect of seniority rather than absolute age, because previous studies showed that seniority has a stronger effect on vocalization than absolute age (Dreiss, Ruppli, Faller, \& Roulin, 2013; Dreiss, Ruppli, \& Roulin, 2014). Nestlings were kept in these boxes for 2 days and 3 nights and then returned to their original nest in the field. After a first night of acclimation, each pair of siblings was recorded twice from 1900 to 2340 hours, one night in a food-deprived state (no food given during the preceding $28 \mathrm{~h}$ ) and another night in a food-satiated state (from 0000 to 1600 hours on the recording day we offered $130 \mathrm{~g}$ of laboratory mice, which exceeds their daily food requirement of $67 \mathrm{~g}$ on average), with the order of the two treatments being randomly assigned across pairs. Individuals that were starved on the first night were randomly chosen, since their mean body mass at the start of the experiment was similar to the mean body mass of individuals receiving food the first night (Student's $t$ test: $t_{202}=0.63, P=0.53$ ). To avoid unnecessary disturbance we handled nestlings only once per day at 1600 hours and opened nestboxes again at midnight to add food. In 10 of the food-deprived pairs (6\% of nestlings) and 24 of the foodsatiated pairs ( $15 \%$ of nestlings), one of the two individuals did not vocalize during the $4.5 \mathrm{~h}$ recording period. This is also sometimes observed in natural conditions, as $15 \%$ of nestlings do not negotiate during the $15 \mathrm{~min}$ preceding the first prey delivery (reanalysis of data set in Dreiss, Lahlah, et al., 2010). Because our aim was to study vocal interactions between two individuals, we performed statistical analyses on the remaining 68 pairs of fooddeprived siblings and 54 pairs of food-satiated siblings. Siblings of the same pair always received the same food treatment, because the conflict over obtaining food is resolved very rapidly when nestlings present different levels of need, the nestling facing a more hungry sibling producing very few calls (11 times less than its sibling on average, data from Roulin, Kolliker, \& Richner, 2000). When in a similar food state, the most vocal nestling only produced four times more calls than its sibling (data from Roulin et al., 2000). 


\section{Playback Experiments}

\section{Playback of natural call series}

In 2009, we broadcast natural sequences of calls produced by a single nestling, which we extracted from the vocal exchanges of sibling pairs recorded in 2008. We selected five sequences of 84 min on average (range 73-93) from five different vocal dyadic interactions, with the criterion that the more voluble nestling did not stop calling for more than $3 \mathrm{~min}$. From these five recordings, we deleted the calls of the less voluble individual and kept intact the calls of its sibling. Such a playback experiment simulates a situation where a live nestling interacts vocally with an individual that does not adjust its vocal behaviour to its opponent. In 2009, 52 nestlings 25-40 days old (mean \pm SE: $34 \pm 1$ ), from 16 nests, were placed on one side of the same wooden nestboxes as those used in 2008, while a loudspeaker (near05 experience, ESI Audiotechnik $\mathrm{GmbH}$, Leonberg, Germany) was placed on the other side broadcasting one of the five sequences. Nestlings were deprived of food from the morning preceding the experiment, at 0800 hours. The experiment started at 0100 hours the following day.

\section{Playback with varying call and pause durations}

In 2011, we broadcast eight 2 min long sequences of calls to 108 single nestlings from 33 nests (20-42 days old, mean \pm SE: $33 \pm 1$ ) placed in the same experimental boxes as those used in 2008 and 2009. Three parameters were manipulated at two levels: call duration, change in call duration and change in pause duration between two calls. Eight playback sequences (constituting all the combinations of the three parameters) were broadcast to each nestling. Playback sequences were composed of 20 calls either longer than the mean call duration usually observed in vocal exchanges between two siblings (0.82-1.00 s, Ruppli et al., 2013) or shorter $(0.60-0.78 \mathrm{~s})$, of either continuously increasing duration ( $0.60-0.78 \mathrm{~s}$ or $0.82-1.00 \mathrm{~s}$ changing by $0.02 \mathrm{~s}$ every two calls) or continuously decreasing duration $(0.78-0.60 \mathrm{~s}$ or $1.00-0.82 \mathrm{~s}$ changing by $0.02 \mathrm{~s}$ every two calls) and separated by either continuously increasing or decreasing pause duration (time interval between two calls starts from 3.05 to $9.94 \mathrm{~s}$, changing by $0.76 \mathrm{~s}$ every two pauses). The eight playback sequences were broadcast in a random order and separated by a silence of $6 \mathrm{~min}$. This playback mimics a situation where an individual can take its turn after its sibling has stopped vocalizing. Nestlings were fed with $50 \mathrm{~g}$ of laboratory mice the morning preceding the experiment, at 0800 hours. The experiment started at 0130 hours.

We extracted the calls needed to compile playback soundtracks from the vocal interactions of five food-deprived individuals recorded in 2008, from five broods. For each individual, we selected 20 calls according to their duration and not modified, except for loudness, which was standardized using Audacity v.1.3 Beta freeware (http://audacity.sourceforge.net). This manipulation did not affect other acoustic parameters. The eight playback sequences broadcast to a single nestling were compiled with the calls of only one playback individual.

\section{Acoustic and Statistical Analyses}

To automatically estimate call timing and call duration, we used Matlab (MathWorks, Natick, MA, U.S.A.), a call being detected when the signal temporal envelope was significantly above the estimated noise level (see more details in Dreiss, Ruppli, Faller, et al., 2013). We recorded two soundtracks from the two microphones (MC930, Beyerdynamic GmbH \& Co KG, Heilbronn, Germany) oriented in opposite directions, each facing one barn owl as the input file. We compared the signal level and timing from the two microphones or of the microphone and playback soundtrack to assign calls to junior or senior siblings and to single nestlings or playback.

Statistical analyses were performed with SAS v.9.1 (SAS Institute Inc., Cary, NC, U.S.A.). All tests are two tailed. Assumptions of homoscedasticity and normal distributions of variables were verified in each test (using Kolmogorov-Smirnov tests).

\section{Preferential production of solos over rapid vocal exchanges}

For each nestling pair, to compare the observed distribution of the number of calls produced in a row without being interrupted we used a random geometric distribution (Appendix Fig. A1). An interruption is defined as calling after a sibling's call; we do not make assumptions here about nestling intent and on whether an individual was interrupted or stopped vocalizing on purpose. If nestlings distribute their calls randomly during the recording period, the probability of producing $x$ calls in a row without being interrupted by the sibling is given by $\operatorname{Pr}(x)=(p)^{x-1}(1-p)$, where $p$ is the probability of calls by focal nestlings, i.e. number of calls produced by the nestling, divided by the total number of calls of the pair. Mean values per pair of nestlings were considered in order to correct for nonindependence of nestlings within pairs. All observed distributions of number of calls produced in a row were significantly different from random expectation in a Kolmogorov test.

\section{Social vocal rules}

To investigate the dynamics of vocal exchanges and the cues affecting nestling investment during a vocal exchange, for each call we analysed the statistical effect of the preceding 10 calls of the vocal exchange on investment in the vocal contest in terms of call and pause duration. We only consider series of 10 calls (produced by the focal nestling or by its sibling) for which pause duration between two successive calls did not exceed $20 \mathrm{~s}$, which corresponds to $98 \%$ of all 251047 recorded pauses. In the analysis of vocal interaction, the term current 'vocal dominance' indicates the proportion of calls produced by the focal nestling during the sequence of the last 10 calls produced by its sibling or the playback (Appendix Fig. A2). For each focal individual and each call, we counted the calls the focal individual produced out of the last 10 preceding calls exchanged by this individual with its sibling or the playback. Then, we computed mean values over all the calls for which the last 10 calls were all produced by its sibling (category $0 \%$ of current 'vocal dominance'). Similarly, we computed mean values over all the calls for which only one of the last 10 calls was produced by the focal individual (category $10 \%$ ) and so on, until we reached the category $100 \%$. Statistical analyses were performed with these mean values, and for each individual we had a maximum of 10 mean values, explaining why each individual was introduced as a random variable to control for pseudoreplication.

We investigated the dynamics of nestling investment during a solo, defined as more than 10 calls produced by one nestling without being vocally interrupted by its sibling (which corresponds to series more common than expected by chance, Appendix Fig. A1). The results were similar when considering 15 or 20 calls (not shown). In the course of solos, the term 'call position' indicates the location (e.g. beginning, middle or end) of a given call in the course of a solo (Appendix Fig. A2). For each individual and each solo, we averaged the values of a given position of calls of the solo (e.g. first $10 \%$ of the solo) and then averaged the values found in all solos from this specific individual.

Dynamics of call and pause durations were analysed with linear mixed models using the residual maximum likelihood method. For the analysis of natural vocal interactions between two live siblings, the two random variables were the order of food treatment and focal nestling identity nested in both the pair of siblings (a given individual was always tested with the same sibling) and in the 
brood in which it was raised in the field. For the analyses of single nestlings responding to playbacks, we included as random variables focal nestling identity nested in both the brood in which it was raised by its parents and the playback sequence (we broadcast to each individual one of five different playback sequences). Model selection was performed by backward elimination of the nonsignificant $(P>0.05)$ terms beginning with the highest order interaction terms. Elimination of nonsignificant terms did not significantly modify the Akaike information criterion (AIC). Final models only contained significant effects and when a two-way interaction term was significant, the main effects involved in the interaction were retained even if nonsignificant.

To investigate the cues inducing nestlings to enter a vocal competition, we examined the factors related to the probability of interrupting a focal individual or that this focal individual stopped calling, i.e. the probability that a call of a focal nestling is followed by a call of its sibling. For each given call, we analysed whether it was followed by a call of the same focal nestling or of its sibling, implemented as a binomial dependent variable in a generalized mixed model. We performed separate analyses for calls produced during a solo (i.e. series of 10 calls produced in a row by the same individual) or during a vocal exchange (series of 10 calls produced by both siblings). For a solo, independent terms were food treatment, seniority and vocal production of the individual in the solo, i.e. mean duration of the last five calls and of the last five pauses, and 'duration variation' of the last five calls and of the last five pauses of the focal nestling. Duration variation was calculated as the regression slope of the duration against call position in the sequence (1-5; Appendix Fig. A2). For vocal exchanges, independent terms were food treatment, seniority and relative vocal production of the two siblings, i.e. the difference between the mean duration of the calls of the focal individual and of its sibling, the difference between the mean interval between the calls of the focal individual and of its sibling, the difference between the 'duration variation' of the calls of the focal individual and of its sibling and the difference between the variation of the last interval between the calls of the focal individual and of its sibling (Appendix Fig. A2). Average and variation values were calculated on the last five calls of the focal individual and its sibling (for vocal exchange), and only if the last five calls were produced during the previous $2 \mathrm{~min}$. This time lapse was chosen because the influence of playback calls on nestlings fades after a few minutes (Ruppli et al., 2013). However, results were qualitatively similar if we modified the criteria (previous 1 or $3 \mathrm{~min}$ and last three calls, not shown). Because individuals vary in their mean call duration (Dreiss et al., 2014), we used a standardized measure of call duration for each individual by dividing each call duration by the average value of all calls. The focal nestling identity nested in both the pair of siblings and in the brood identity was a random factor.

Vocal interactions between live individuals were analysed for 55102 calls by 68 food-deprived seniors, 25680 calls by 54 foodsatiated seniors, 83694 calls by 68 food-deprived juniors and 51436 calls by 54 food-satiated juniors. We analysed the 8711 calls produced by the 52 single individuals facing a playback sequence. Solos of individuals interacting with a live sibling were analysed for the 1135 solos ( 33204 calls) by 68 food-deprived seniors, 545 solos ( 21665 calls) by 54 food-satiated seniors, 1653 solos (65772 calls) by 68 food-deprived juniors and 1005 solos (48324 calls) by 54 food-satiated juniors. We considered the 700 uninterrupted playback solos broadcast to single individuals.

\section{Playback with varying call and pause durations}

The latency (s) a nestling waited before calling after the end of a playback was normalized by a log transformation. Latency was analysed in relation to (1) the change in duration of the broadcast calls (increased or decreased duration during the playback) (2) the change in the rate at which calls were broadcast (increased or decreased rate during the playback) and (3) the absolute call duration of the playback (short or long). This was done using a linear mixed model considering the 90 nestlings that called at least once during the 6 min of silence following a playback sequence. The order in which we broadcast playback sequences was included as a covariate and we incorporated as random factors the individual used to generate the playback sequence and the nestling identity nested in the brood in which it was raised in the field.

\section{Ethical Note}

We brought barn owl nestlings into the laboratory at an age at which they were able to consume food and thermoregulate without maternal help. For these reasons, the mother usually stops sleeping with her offspring during the daylight hours and comes back to the nest only at night to deliver food items. We carried out our laboratory experiments on offspring that were accustomed to their mother's absence. Temporarily removing several nestlings never induced parents to abandon their nest. Keeping owlets in captivity and food depriving them for several hours did not negatively affect their body condition: mean body mass and survival at fledgling did not differ significantly between the siblings that were or were not brought into captivity (Wilcoxon paired signed-rank test on mean body mass of recorded and nonrecorded siblings per brood: $S=13.5, P=0.69$; on mean survival: $S=8, N=41, P=0.22$ ). Nestlings brought to the laboratory did not differ significantly in body mass before the experiment from nestlings left in the nest (Wilcoxon paired signed-rank test on mean body mass of recorded and nonrecorded siblings per brood: $S=38.5, P=0.48$ ). We have already shown that nestlings were not physiologically stressed in the laboratory, as shown by the absence of a rise in baseline corticosterone level compared to the situation prevailing under natural, undisturbed conditions (Dreiss, Henry, Ruppli, Almasi, \& Roulin, 2010). The experiments were approved by the veterinary services of Vaud canton (form no. 2109.1). See Dreiss et al. (2013) for further details on transport and origin of the mice.

\section{RESULTS AND DISCUSSION}

Pairs of barn owl siblings communicated by producing 'solos', defined as more than 10 calls produced by one nestling without being vocally interrupted by its sibling (see Methods), or through frequent vocal alternation (i.e. individuals interrupt one another rapidly; Fig. 1). Most calls (67\%) were produced in the form of short to long solos rather than in dyadic vocal interactions, which is more often than would be expected by chance (paired $t$ test between observed and expected proportions of solos for 68 pairs of siblings: $t_{67}=3.96, P=0.0002$; Appendix Fig. A1). This suggests that vocal alternation is a necessary phase to settle the contest over which individual will vocalize alone and hence become 'vocally dominant' over its sibling and increase the likelihood of being fed later on by a parent (Roulin, 2002).

As expected when the asymmetry in food need between the two siblings was experimentally reduced, it was not always the same individual that vocalized alone in a solo and we observed temporal fluctuation in the extent to which an individual was 'vocally dominant' (Fig. 1). We hence first determined which social vocal rules govern nestlings' investment at each time point of a vocal interaction and how individuals became 'vocally dominant'. Then, we defined the social turn-taking rules that allow a nestling to interrupt the partner's solo. These rules will inform us about how an individual is able to dominate a vocal contest by silencing (at least momentarily) its partner and vocalizing alone in a solo. 


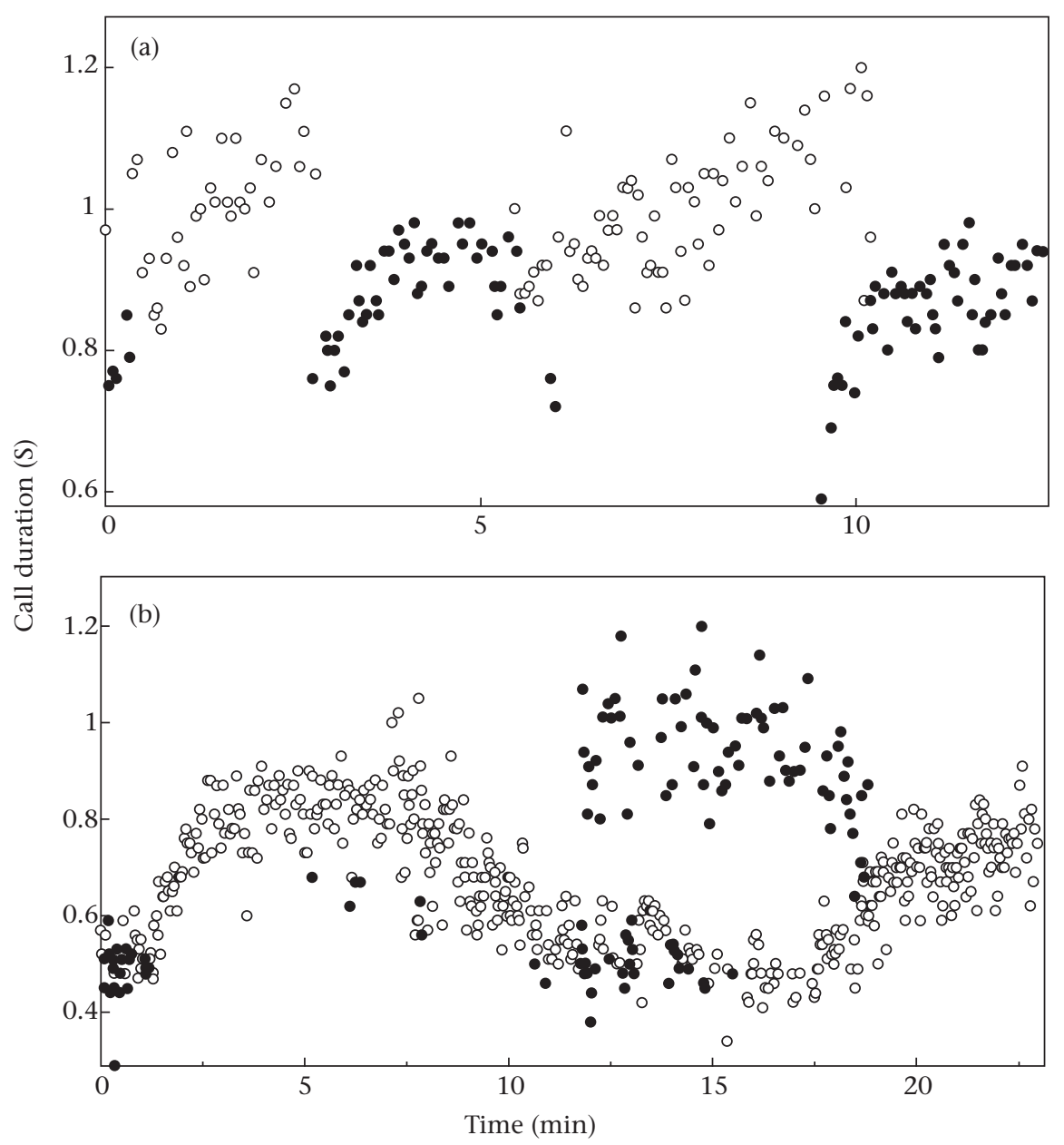

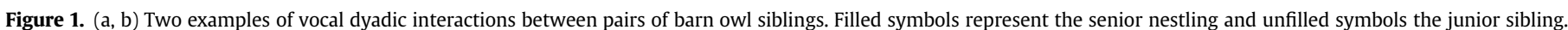

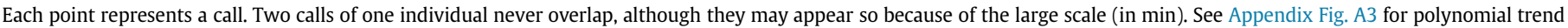
lines on call and pause durations.

\section{Social Vocal Rules Governing Nestlings' Vocal Investment}

The very first call of an individual produced after its sibling's solo was particularly short and was produced with a relatively long latency after the end of the sibling's solo (Fig. 2a, c, Appendix Fig. A4 for error bars). During the exchange, as an individual became 'vocally dominant' over its sibling, it gradually produced longer calls (Fig. 2a, Table 1) and replied faster after a sibling's call (Fig. 2c, Table 1); concomitantly it increased the pause between its own calls (Fig. 2b, Table 1). These patterns were similar in seniors and juniors and weakly influenced by hunger level (Fig. 2a, b, c, Table 1). For 'momentarily vocally dominant' individuals, pauses following the opponent's calls were on average shorter than pauses following their own calls (Fig. 2b, c, effect of identity of previous caller when vocal dominance $>50 \%: F_{1,1810}=809.29, P<0.0001$; same model as in Table 1, regrouping both pauses following opponent and own call in the same mixed model). Conversely, momentarily 'vocally dominated' individuals produced calls after longer pauses following the opponent's calls than after their own calls (Fig. 2b, c, effect of identity of previous caller when vocal dominance $<20 \%$ : $F_{1,4137}=20.39, P<0.0001$; interaction 'vocal dominance' $*$ identity of previous caller: $F_{1,4137}=460.95, P<0.0001$ ).

To experimentally test whether barn owl siblings use their shortterm vocal dominance at a given time point to decide how much they continue to invest in calling, we performed a first playback experiment of natural call series, The 52 single nestlings that heard the playback behaved in a similar way to that of individuals interacting with a live sibling (dashed lines in Fig. 2a, b, c, Table 1). When nestlings became 'vocally dominant' compared to the playback, they produced longer calls, replied faster after being interrupted by a playback call but increased pause duration between their own calls (dashed lines in Fig. 2a, b, c). Conversely, when the playback was 'vocally dominant' (i.e. had more calls than the live nestling) nestlings produced shorter calls and replied more slowly after being interrupted by a playback call (dashed lines in Fig. 2a, b, c). Once the playback became silent, nestlings progressively increased not only call duration but also the pauses between two successive calls; when the playback call rate increased, nestlings produced shorter calls separated from each other by short pauses.

Hence, individuals increased their call duration along with their current 'vocal dominance' in the contest. Call duration of sibling pairs was also positively correlated in natural vocal exchanges (Roulin, Dreiss, Fioravanti, \& Bize, 2009) and when nestlings responded to a broadcast natural sequence (effect of playback call duration in a given minute on the duration of calls produced by the live nestling during the same minute: $F_{1,1610}=8.13, P=0.004$; controlling for nestling and playback call rate: $F_{1,1610}=31.29$, $P<0.0001$ and $F_{1,1610}=15.65, P<0.0001$, respectively, in a mixed model with nestling identity nested in brood and playback identity as random factors). Because calls intermittently lengthen and 
Vocal interactions
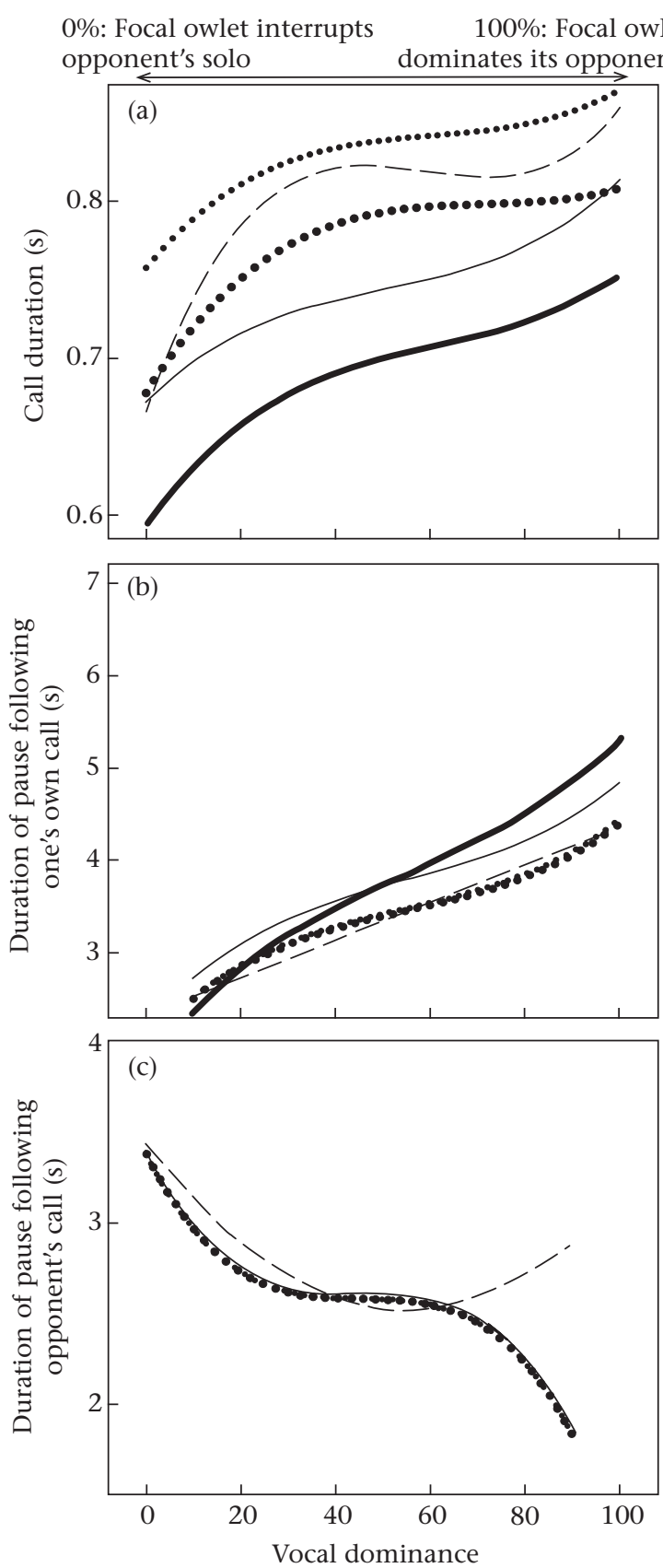

Solos

0\%: Focal owlet $\quad 100 \%$ : Focal owlet

starts a solo ends a solo
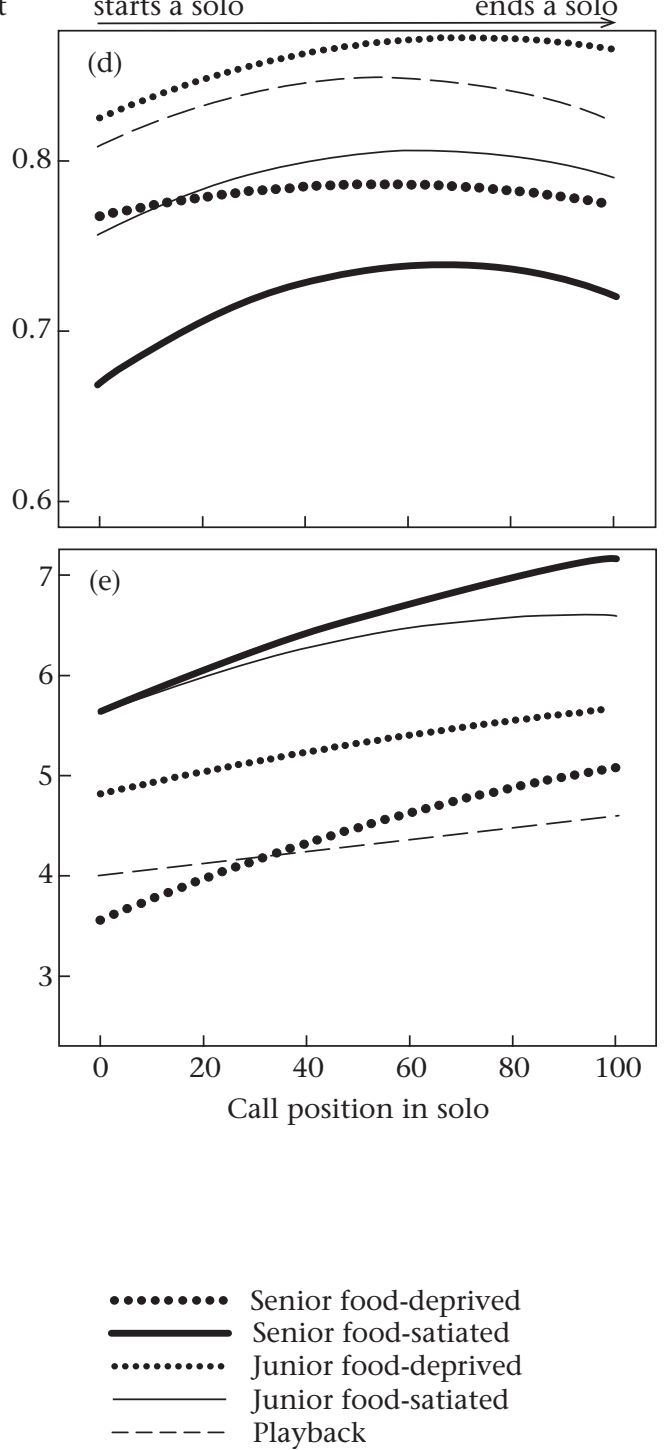

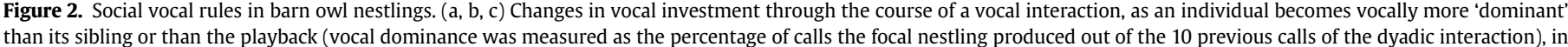

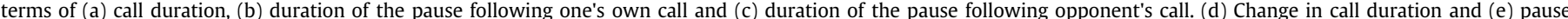

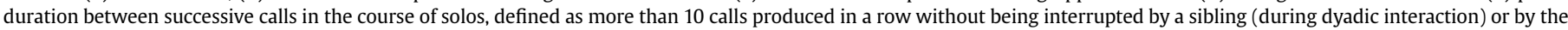

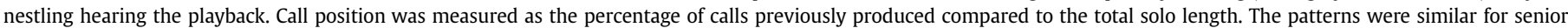

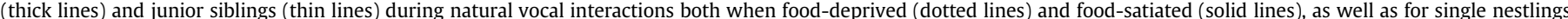

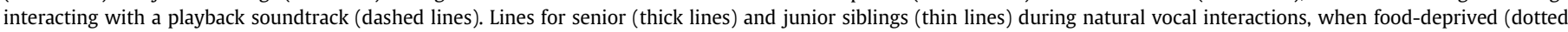

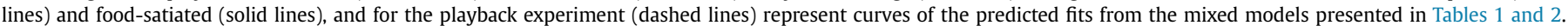

shorten with time, this positive correlation is not due to an increasing hunger level during the experiment. Adjusting one's own call duration to that of the opponent could be a way to optimize investment in vocalization. By this means, individuals would challenge each other and assess each other's motivation, until one individual abandons the contest. Indeed, individuals were more likely to be interrupted when they produced slightly shorter calls than their sibling (probability that a call was followed by a sibling's call was negatively related to the difference in call duration between the focal individual and its sibling: $F_{1,77} 094=38.48$, $P<0.0001$; and to differences in call interval and variation in call interval: $\quad F_{1,77} \quad 094=116.09, \quad P<0.0001 ; \quad F_{1,77} \quad 094=115.52$, $P<0.0001$; no effect of the differences in variation of call duration $\left.F_{1,77094}=0.65, P=0.42\right)$. 
Table 1

Social rules of vocal investment in the course of vocal interaction, between two barn owl siblings and of a single nestling responding to a prerecorded playback sequence

\begin{tabular}{llll}
\hline & $\begin{array}{l}\text { Natural vocal } \\
\text { exchanges between } \\
\text { pairs of siblings }\end{array}$ & & $\begin{array}{l}\text { Single nestling } \\
\text { responding } \\
\text { to playback }\end{array}$ \\
\cline { 2 - 4 } & $\frac{d f}{F}$ & $\frac{d f}{F}$ \\
\hline
\end{tabular}

Call duration (Fig. 2a)

Effects

Vocal dominance (VD)

$\mathrm{VD}^{2}$

$\mathrm{VD}^{3}$

Food treatment (Food)

Age hierarchy

VD $\times$ Food

VD $\times$ Age hierarchy

Food $\times$ Age hierarchy

VD $\times$ Food

$\mathrm{VD}^{2} \times$ Age hierarchy

VD $\times$ Age hierarchy $\times$ Food

Duration of pause following (Fig. 2b)

Vocal dominance (VD)

$\mathrm{VD}^{2}$

$\mathrm{VD}^{3}$

Food treatment (Food)

Age hierarchy

VD $\times$ Food

VD $\times$ Age hierarchy

Food $\times$ Age hierarchy

$\mathrm{VD}^{2} \times$ Food

$\mathrm{VD}^{2} \times$ Age hierarchy

VD $\times$ Age hierarchy $\times$ Food

Duration of pause following op

Vocal dominance (VD)

$\mathrm{VD}^{2}$

$\mathrm{VD}^{3}$

Food treatment (Food)

Age hierarchy

VD $\times$ Food

VD $\times$ Age hierarchy

Food $\times$ Age hierarchy

$\mathrm{VD}^{2} \times$ Food

$\mathrm{VD}^{2} \times$ Age hierarchy

VD $\times$ Age hierarchy $\times$ Food

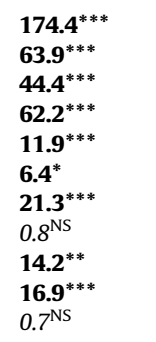

1,2215

1,2215

43.0***

1,368

1,368

1,2215

1,2215

27.5***

1,368

1,2215

1,2215

1,2215

1,2215

1,2215

1,2215

1,2214

22.9***

9.7*

9.9*

$0.1^{\mathrm{NS}}$

$1.3^{\mathrm{NS}}$

$13.8^{* *}$

5.8*

$1.9^{\mathrm{NS}}$

$1.7^{N S}$

$1.2^{\mathrm{NS}}$

6.3*

$-$

$-$

$-$

$-$

$-$

$-$

$\begin{array}{lll}\mathbf{1 , 1 9 1 4} & \mathbf{4 4 . 9}^{* * *} & \mathbf{1 , 3 0 2} \\ \mathbf{1 , 1 9 1 4} & 0.1^{N S} & 1,301 \\ \mathbf{1 , 1 9 1 4} & 0.2^{N S} & 1,300 \\ 1,1914 & - & - \\ 1,1914 & - & -\end{array}$

Vocal dominance of the focal nestling in the exchange is the proportion of calls this nestling produced in the preceding sequence of 10 calls. $\mathrm{VD}^{2}$ and $\mathrm{VD}^{3}$ indicate nonlinear (squared and cubed, respectively) variation in vocal production. Terms eliminated from saturated models are italicized. Significant terms are in bold. ${ }^{*} P<0.05 ;{ }^{* *} P<0.001 ;{ }^{* * *} P<0.0001$.

\section{Turn-taking Rules to Enter a Vocal Contest}

Once an individual had succeeded in monopolizing the current vocal interaction, it vocalized alone in a solo that could last up to $114 \mathrm{~min}$ and up to 1591 calls, without being interrupted by its sibling. How did an owlet manage to keep vocalizing alone over such long solos? What cues did its sibling use to vocally interrupt these solos or under which condition did the individual that was producing a solo stop vocalizing? We analysed vocal behaviour from the start to the end of solos containing more than 10 calls (mean \pm SE: $39 \pm 1$ calls). Once an individual had monopolized the floor it progressively produced longer (Fig. 2d, Table 2) but fewer calls per min (Fig. 2e, Table 2). Its silent sibling waited for calls to become shorter again to interrupt the solo (Fig. 2d, Table 2). These temporal patterns in call and pause duration were found in seniors and juniors, and in both food-satiated and food-deprived siblings (Fig. 2d, e, Appendix Fig. A5 for error bars, Table 2) and were also confirmed by the playback experiment. When hearing a playback, single owlets waited for playback calls to become shorter before taking their turn (dashed line in Fig. 2d, Table 2). As a corollary,
Table 2

Vocal investment in the course of solos in barn owl nestlings and turn-taking rules

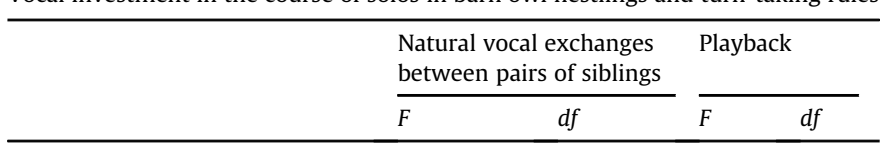

Call duration (Fig. 2d)

Effects

Call position in solo (Position)

Position $^{2}$

Food treatment (Food)

Age hierarchy

Position $\times$ Food

Position $\times$ Age hierarchy

Food x Age hierarchy

Position $^{2} \times$ Food

Position $^{2} \times$ Age hierarchy

Position $\times$ Food $\times$ Age hierarchy 25.4 $^{* * *}$

Pause duration between successive calls (Fig. 2e)

Call position in solo (Position)

Position $^{2}$

Food treatment (Food)

Age hierarchy

Position $\times$ Food

Position $\times$ Age hierarchy

Food $\times$ Age hierarchy

Position $^{2} \times$ Food

Position $^{2} \times$ Age hierarchy

Position $\times$ Food $\times$ Age hierarchy $0.19^{N S}$

$\begin{array}{ll}\mathbf{2 2 0 . 0}^{* * *} & \mathbf{1 , 2 2 8 0} \\ \mathbf{1 3 8 . 8}^{* * *} & \mathbf{1 , 2 2 8 0} \\ \mathbf{9 6 . 3}^{* * *} & \mathbf{1 , 2 2 8 0} \\ \mathbf{5 . 0}^{*} & \mathbf{1 , 2 2 8 0} \\ \mathbf{1 7 . 7}^{* * *} & \mathbf{1 , 2 2 8 0} \\ 0.2^{\mathrm{NS}} & 1,2280 \\ 0.1^{\mathrm{NS}} & 1,2280 \\ \mathbf{1 1 . 3}^{* *} & \mathbf{1 , 2 2 8 0} \\ 0.1^{N S} & 1,2279 \\ \mathbf{2 5 . 4}^{* * *} & \mathbf{1 , 2 2 8 0}\end{array}$

$64.9^{* * *} \quad 1,518$

$56.4^{* * *} \quad 1,518$

$-$

$-\quad-$

$-$

$-$

$-$

$-1$

A solo is a series of more than 10 calls produced in a row by a single individual without being interrupted by its sibling or produced by a prerecorded playback sequence without being interrupted by the nestling listening to it. The duration of calls and of pauses between successive calls were analysed in relation to the position of the calls in the solo (e.g. beginning, middle or end), food treatment (the two vocally interacting siblings were both experimentally food-deprived or both foodsatiated) and age hierarchy (senior versus junior). Terms eliminated from initial models are italicized. Significant terms are in bold.

${ }^{*} P<0.05 ;{ }^{* *} P<0.001 ;{ }^{* *} P<0.0001$

during dyadic interactions the probability of interrupting a solo increased when the caller produced vocalizations decreasing in duration $\left(F_{1,106} 400=28.06, P<0.0001\right)$ and call rate $\left(F_{1,106}\right.$ $400=4.63, P=0.031)$. Sibling interruptions were also more frequent when average call duration was lower $\left(F_{1,106} 400=43.43\right.$, $P<0.0001$ ), but were not related to average pause duration between two successive calls produced by the focal individual $\left(F_{1,106}\right.$ $400=1.76, P=0.18$ ).

Hence, the decision to resume vocal activities is associated with call duration and both increasing pause duration and decreasing call duration in the sibling's solo (Fig. 2d, e). Our second playback experiment with varying call and pause durations was aimed at disentangling the roles of these three vocal components. On average the single nestlings vocalized sooner after the playback when both duration and rate of the broadcast calls were decreasing during the playback sequence (Table 3, Fig. 3). The latency after playback was longer than in natural dialogue (29.0 versus $3.3 \mathrm{~s}$ ), which could be explained by two main factors. Either nestlings were generally less motivated to call (less hungry) or they were less stimulated by the artificial playback. Average playback call duration did not significantly affect nestlings' vocal behaviour (Table 3).

\section{CONCLUSION}

Barn owl siblings vocally compete for hours. During this long vocal interaction, nestlings avoid overlapping calls (Dreiss, Ruppli, Oberli, et al., 2013) and refrain from calling when facing a highly vocal competitor (Ruppli et al., 2013). These findings were all based on the analyses of average signalling levels, whereas in the present study we considered each single call to tackle the temporal 
Table 3

Time taken (i.e. calling latency) by nestling barn owls before calling at the end of playback for which both the duration of broadcast calls and the pause between two successive broadcast calls varied

\begin{tabular}{lll}
\hline Effects & $F$ & $d f$ \\
\hline Order of the four playback sequences & $0.3^{N S}$ & 1,438 \\
Change in playback's call duration (increase vs decrease) & $\mathbf{4 . 4}^{*}$ & $\mathbf{1 , 4 3 8}$ \\
$\quad(\mathrm{CC})$ & & \\
Change in playback's pause durations (increase vs decrease) & $\mathbf{5 . 0}^{*}$ & $\mathbf{1 , 4 3 8}$ \\
$\quad(\mathrm{CP})$ & $3.4^{\mathrm{NS}}$ & 1,438 \\
Mean playback's call duration (long vs short) (MC) & $1.8^{\mathrm{NS}}$ & 1,435 \\
CC $\times$ CP & $0.2^{N S}$ & 1,435 \\
CC $\times$ MC & $0.8^{N S}$ & 1,435 \\
CP $\times$ MC & $1.0^{N S}$ & 1,434 \\
CC $\times$ CP $\times$ MC & & \\
\hline
\end{tabular}

Terms eliminated from saturated models are italicized. Significant terms are in bold. ${ }^{*} P<0.05$.

dynamics of call production. This approach allowed us to describe the turn-taking rules leading one individual to vocally dominate an interaction, i.e. to produce a long solo after having silenced its sibling. We showed that barn owl siblings constantly modulated their current investment in vocal behaviour according to vocal social rules, independently of hunger level (Fig. 4). The proximate mechanism leading to the modulation of call timing may be due to nestlings resetting their calling onset when perceiving a nestmate's call (Greenfield et al., 1997; Takahashi, Narayanan, \& Ghazanfar, 2013), but with an additional complexity, as past relative investment and change in investment influenced the current calling decision. Ultimately, temporally organizing vocal production according to a competitor's signal is probably a way to optimize signal efficiency (Ficken, Ficken, \& Hailman, 1974; Gerhardt, 1994; Tobias et al., 2004), as discussed below.

In the barn owl, the variation in two simple parameters of a hissing call (duration and rate) determines the alternation of vocalizations between two individuals. The average call duration and rate vary among individuals, but organization rules of vocal communication remain the same. The sensitivity of barn owl nestlings to the partner's change in duration and rate in the preceding vocal sequence is an additional element showing that animals perceive complex vocal patterns (Rek \& Osiejuk, 2010). Some species organize their vocal units following syntactic rules (ten Cate \&
Okanoya, 2012; Ouattara, Lemasson, \& Zuberbuhler, 2009); the organization found in barn owls can be seen as a precursor of syntactic rules without any differentiated vocal units (Rek \& Osiejuk, 2010).

According to the social rules demonstrated here, each nestling invests in vocalization in relation to its current 'vocal dominance' in the interaction, hence to its own past investment in the contest and to the past investment of its nestmate. This is consistent with individuals investing as a function of their likelihood of obtaining the next food item delivered by a parent. A nestling that has already invested substantial effort to become 'vocally dominant' would lose this investment if vocally outcompeted by a sibling just before a parent arrives. This would explain why 'vocally dominant' nestlings rapidly interrupted their opponent (Fig. 2c), which is perceived as a competitive signal (Dreiss, Ruppli, Faller, et al., 2013). Moreover, call durations of siblings were correlated, suggesting that individuals optimize their investment in competition by producing calls just long enough (i.e. once a sibling produces slightly longer calls, a focal individual started to produce a slightly longer call in an attempt to dominate the interaction). In many songbirds, song matching, which consists of imitating a competitor's song type, is often perceived as a threat signal (Searcy \& Beecher, 2009).

When no longer challenged, a currently 'vocally dominant' nestling increased pause duration between its own calls (Fig. 2b, e), which is consistent with individuals attempting to reduce the cost of communication. However, it maintained a high call duration (Fig. 2a, d), probably as a means of signalling its willingness to compete and continue to dominate the vocal interaction. Once its call duration decreased, the opponent perceived this decrease as a signal to re-enter the vocal contest (Figs $2 \mathrm{~d}$ and 3 ). Why should 'vocally dominant' individuals decrease their vocal investment at the risk of being challenged again? Two main hypotheses could be proposed. Either fatigue prevents nestlings from producing long calls during extended periods. Alternatively, individuals may give the floor to their competitor to reassess its vocal motivation level, in order to optimally adjust effort in the competition. It would be pointless to keep calling at high intensity if competitor siblings are no longer motivated. This temporal dynamics of signal exchange appears adaptive for the two interacting siblings because "vocally dominant' nestlings do not signal at maximal level and 'vocally dominated' opponents repeatedly challenge the honesty of the signal. A previous study in the barn owl has shown that offspring

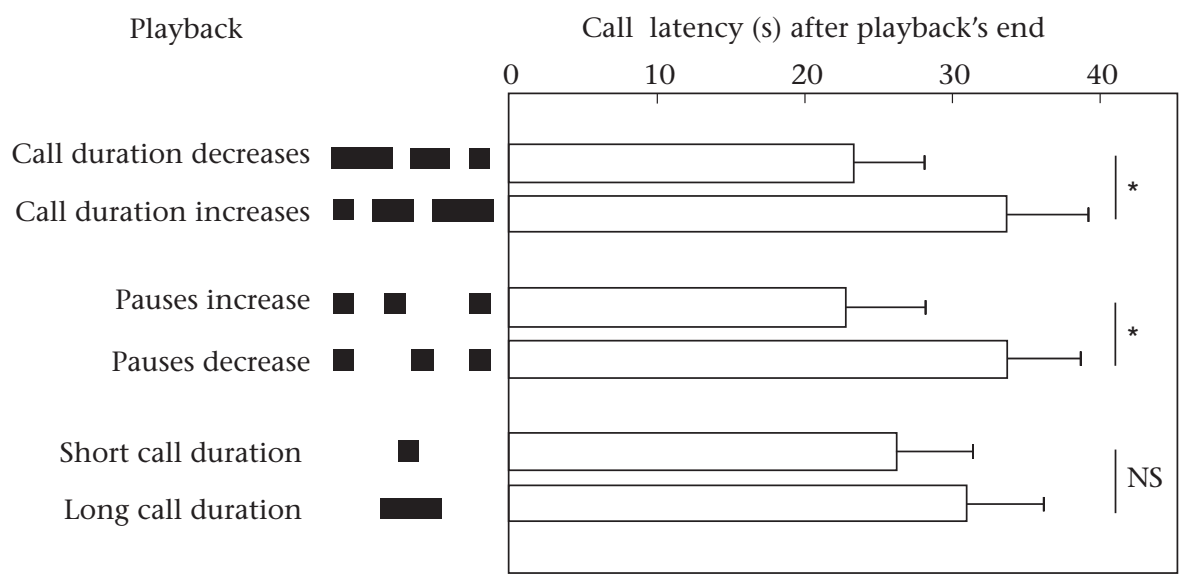

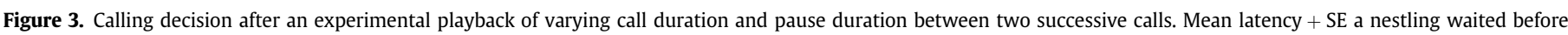

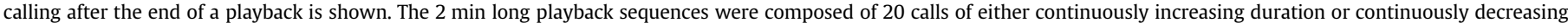

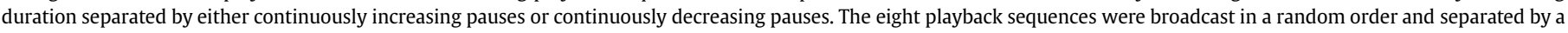
silence of $6 \mathrm{~min}$. Asterisks represent a significant difference $(P<0.05)$. 


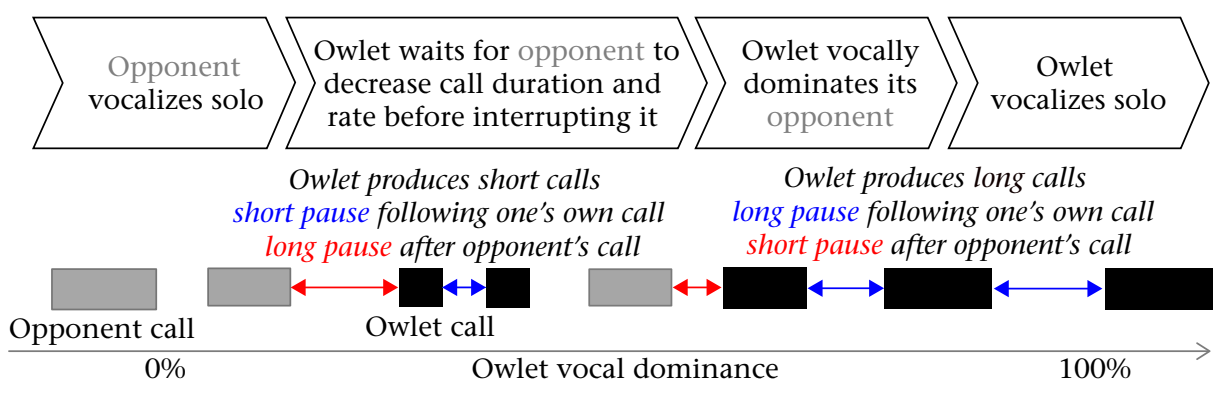

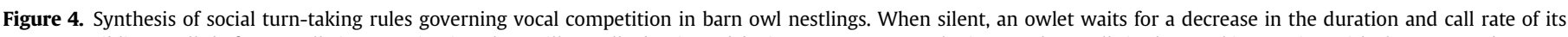

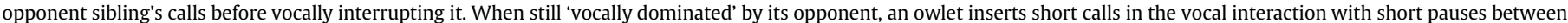

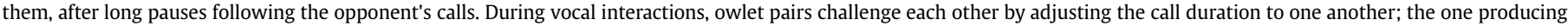

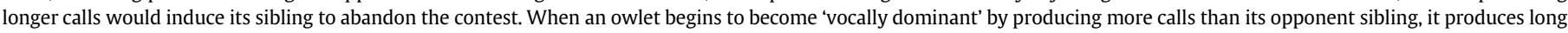

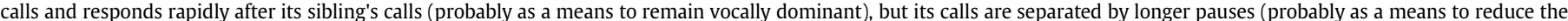
cost of communication).

calling behaviour in the absence of parents does not influence feeding rate (Roulin et al., 2000). It is hence unlikely that nestlings decrease their vocal investment so that siblings cooperatively take their turn to vocally motivate their parents to bring food to the nest (Johnstone, 2004).

The way two individuals resolve a conflict of interest by communicating is determined not only by hierarchy (e.g. seniority) and internal state (e.g. hunger level), but also by social rules based on the opponent's vocal production. In social science, conversation analysts postulate that humans adhere to implicit conversational rules that establish when to alternate turns or continue speaking (Duncan, 1972; Jaffe, Beebe, Feldstein, Crown, \& Jasnow, 2001; Sacks, Schegloff, \& Jefferson, 1974). As in human conversation (Stivers et al., 2009), the basic turn-taking rules demonstrated here do not depend on family, context of the social interaction, age hierarchy or hunger level. Although seniority influences vocal production with juniors producing more, longer and louder calls than seniors (Dreiss, Lahlah, et al., 2010; Dreiss et al., 2014; present study), turn-taking rules are similar in junior and senior siblings. Turn-taking rules, which allow each individual to determine when and how to start signalling, have only been described in a cooperative vocal exchange, such as duetting birds (Logue, Chalmers, \& Gowland, 2008) and contact calls in some monkeys (Biben, Symmes, \& Masataka, 1986; Hauser \& Fowler, 1992; Takahashi et al., 2013), during antiphonal exchange of rapid phrases. Here, we have demonstrated the existence of turn-taking rules in a competitive context in a nonsocial animal. Such rules should thus be widespread in nonhuman animals and could be more important than previously thought for the resolution of animal conflicts.

\section{Acknowledgments}

We thank Louis-Félix Bersier, Sylvain Antoniazza, Anthony Davison, Raphaelle Flint, Alexandre Chausson, Isabelle Henry, Alain Zuur, Philippe Christe, Andy Horn and Kate Lessells and two anonymous referees for comments, Camille Toscani and Marion Podolak for their assistance on the field, and the Swiss Science Foundation (No 143353) for financial support.

\section{References}

Biben, M., Symmes, D., \& Masataka, N. (1986). Temporal and structural analysis of affiliative vocal exchanges in squirrel monkeys (Saimiri sciureus). Behaviour, 98 259-273. http://dx.doi.org/10.1163/156853986x00991.

Briffa, M., Elwood, R. W., \& Dick, J. T. A. (1998). Analysis of repeated signals during shell fights in the hermit crab Pagurus bernhardus. Proceedings of the Royal Society B: Biological Sciences, 265(1404), 1467-1474.

Bühler, P., \& Epple, W. (1980). Die Lautäußerungen der Schleiereule (Tyto alba). Journal of Ornithology, 121, 36-70.
Bulmer, E., Celis, P., \& Gil, D. (2008). Parent-absent begging: evidence for sibling honesty and cooperation in the spotless starling (Sturnus unicolor). Behavioral Ecology, 19(2), 279-284.

ten Cate, C., \& Okanoya, K. (2012). Revisiting the syntactic abilities of non-human animals: natural vocalizations and artificial grammar learning. Philosophical Transactions of the Royal Society B: Biological Sciences, 367(1598), 1984-1994. http://dx.doi.org/10.1098/rstb.2012.0055.

Dobler, R., \& Kolliker, M. (2009). Behavioural attainability of evolutionarily stable strategies in repeated interactions. Animal Behaviour, 77(6), 1427-1434. http:// dx.doi.org/10.1016/j.anbehav.2009.02.013.

Dreiss, A. N., Calcagno, M., van den Brink, V., Laurent, A., Almasi, B., Jenni, L., et al. (2013). The vigilance components of begging and sibling competition. Journal of Avian Biology, 44(4), 359-368. http://dx.doi.org/10.1111/j.1600048X.2013.00066.x.

Dreiss, A. N., Henry, I., Ruppli, C., Almasi, B., \& Roulin, A. (2010a). Darker eumelanic barn owls better withstand food depletion through resistance to food deprivation and lower appetite. Oecologia, 164(1), 65-71.

Dreiss, A. N., Lahlah, N., \& Roulin, A. (2010b). How siblings adjust sib-sib communication and begging signals to each other. Animal Behaviour, 80, 1049-1055.

Dreiss, A. N., Ruppli, C. A., Faller, C., \& Roulin, A. (2013a). Big brother is watching you: eavesdropping to resolve family conflicts. Behavioral Ecology, 24(3), 717-722. http://dx.doi.org/10.1093/beheco/ars210.

Dreiss, A. N., Ruppli, C. A., Oberli, F., Antoniazza, S., Henry, I., \& Roulin, A. (2013b). Barn owls do not interrupt their siblings. Animal Behaviour, 86, 119-126. http:// dx.doi.org/10.1016/j.anbehav.2013.04.019.

Dreiss, A. N., Ruppli, C. A., \& Roulin, A. (2014). Individual vocal signatures in barn owl nestlings: does individual recognition have an adaptive role in sibling vocal competition? Journal of Evolutionary Biology, 27(1), 63-75. http://dx.doi.org/ $10.1111 /$ jeb.1227.

Duncan, S. (1972). Some signals and rules for taking speaking turns in conversations. Journal of Personality and Social Psychology, 23(2), 283-292.

Enquist, M., \& Leimar, O. (1983). Evolution of fighting behavior: decision rules and assessment of relative strength. Journal of Theoretical Biology, 102(3), 387-410. http://dx.doi.org/10.1016/0022-5193(83)90376-4.

Enquist, M., Leimar, O., Ljungberg, T., Mallner, Y., \& Segerdahl, N. (1990). A test of the sequential assessment game: fighting in the cichlid fish Nannacara anomala. Animal Behaviour, 40, 1-14. http://dx.doi.org/10.1016/s00033472(05)80660-8.

Ficken, R. W., Ficken, M. S., \& Hailman, J. P. (1974). Temporal pattern shifts to avoid acoustic interference in singing birds. Science, 183(4126), 762-763.

Gerhardt, H. C. (1994). The evolution of vocalization in frogs and toads. Annual Review of Ecology and Systematics, 25, 293-324. http://dx.doi.org/10.1146/ annurev.ecolsys.25,1.293.

Godfray, H. C. J. (1991). Signaling of need by offspring to their parents. Nature, 352(6333), 328-330. http://dx.doi.org/10.1038/352328a0.

Greenfield, M. D., Tourtellot, M. K., \& Snedden, W. A. (1997). Precedence effects and the evolution of chorusing. Proceedings of the Royal Society B: Biological Sciences, 264(1386), 1355-1361.

Hauser, M. D., \& Fowler, C. A. (1992). Fundamental frequency declination is not unique to human speech: evidence from nonhuman primates. Journal of the Acoustical Society of America, 91(1), 363-369. http://dx.doi.org/10.1121/ 1.402779 .

Jaffe, J., Beebe, B., Feldstein, S., Crown, C. L., \& Jasnow, M. D. (2001). Rhythms of dialogue in infancy. Monographs of the Society for Research in Child Development, 66(2), 1-132.

Johnstone, R. A. (2004). Begging and sibling competition: how should offspring respond to their rivals? American Naturalist, 163(3), 388-406.

Johnstone, R. A., \& Hinde, C. A. (2006). Negotiation over offspring care-how should parents respond to each other's efforts? Behavioral Ecology, 17(5), 818-827. http://dx.doi.org/10.1093/beheco/arl009. 
Johnstone, R. A., \& Roulin, A. (2003). Sibling negotiation. Behavioral Ecology, 14(6), $780-786$.

Kilner, R. M., Noble, D. G., \& Davies, N. B. (1999). Signals of need in parent-offspring communication and their exploitation by the common cuckoo. Nature, 397(6721), 667-672.

Logue, D. M., Chalmers, C., \& Gowland, A. H. (2008). The behavioural mechanisms underlying temporal coordination in black-bellied wren duets. Animal Behaviour, 75, 1803-1808. http://dx.doi.org/10.1016/j.anbehav.2007.10.036.

Madden, J. R., Kunc, H. P., English, S., Manser, M. B., \& Clutton-Brock, T. H. (2009). Calling in the gap: competition or cooperation in littermates' begging behaviour? Proceedings of the Royal Society B: Biological Sciences, 276(1660), 1255-1262.

Maynard Smith, J. (1982). Do animals convey information about their intentions? Journal of Theoretical Biology, 97, 1-5.

McNamara, J. M., Gasson, C. E., \& Houston, A. I. (1999). Incorporating rules for responding into evolutionary games. Nature, 401(6751), 368-371.

Nash, J. (1950). The bargaining problem. Econometrica, 18, 155-162.

Ouattara, K., Lemasson, A., \& Zuberbuhler, K. (2009). Campbell's monkeys concatenate vocalizations into context-specific call sequences. Proceedings of the $\mathrm{Na}$ tional Academy of Sciences of the United States of America, 106(51), 22026-22031.

Parker, G. A. (1974). Assessment strategy and evolution of fighting behavior. Journal of Theoretical Biology, 47, 223-243.

Patricelli, G. L., Krakauer, A. H., \& McElreath, R. (2011). Assets and tactics in a mating market: economic models of negotiation offer insights into animal courtship dynamics on the lek. Current Zoology, 57(2), 225-236.

Patricelli, G. L., Uy, J. A. C., Walsh, G., \& Borgia, G. (2002). Sexual selection: male displays adjusted to female's response. Nature, 415, 279-280.

Payne, R. J. H., \& Pagel, M. (1996). Escalation and time costs in displays of endurance. Journal of Theoretical Biology, 183(2), 185-193. http://dx.doi.org/10.1006/ jtbi.1996.0212.

Rek, P., \& Osiejuk, T. S. (2010). Sophistication and simplicity: conventional communication in a rudimentary system. Behavioral Ecology, 21(6), 1203-1210. http://dx.doi.org/10.1093/beheco/arq143.

Roulin, A. (2002). The sibling negotiation hypothesis. In J. Wright, \& M. L. Leonard (Eds.), The evolution of begging: Competition, cooperation and communication (pp. 107-127). Dordrecht, Germany: Kluwer Academic Press.
Roulin, A., Dreiss, A. N., Fioravanti, C., \& Bize, P. (2009). Vocal sib-sib interactions: how siblings adjust signalling level to each other. Animal Behaviour, 77(3), 717-725.

Roulin, A., Kolliker, M., \& Richner, H. (2000). Barn owl (Tyto alba) siblings vocally negotiate resources. Proceedings of the Royal Society B: Biological Sciences, 267(1442), 459-463.

Ruppli, C. A., Dreiss, A. N., \& Roulin, A. (2013). Efficiency and significance of multiple vocal signals in sibling competition. Evolutionary Biology, 40(4), 579-588. http://dx.doi.org/10.1007/s11692-013-9233-8.

Sacks, H., Schegloff, E. A., \& Jefferson, G. (1974). Simplest systematics for organization of turn-taking for conversation. Language, 50(4), 696-735.

Searcy, W. A., \& Beecher, M. D. (2009). Song as an aggressive signal in songbirds. Animal Behaviour, 78(6), 1281-1292. http://dx.doi.org/10.1016 j.anbehav.2009.08.011.

Sirot, E. (2012). Negotiation may lead selfish individuals to cooperate: the example of the collective vigilance game. Proceedings of the Royal Society B: Biological Sciences, 279, 2862-2867.

Stivers, T., Enfield, N. J., Brown, P., Englert, C., Hayashi, M., Heinemann, T., et al. (2009). Universals and cultural variation in turn-taking in conversation. Proceedings of the National Academy of Sciences of the United States of America, 106(26), 10587-10592. http://dx.doi.org/10.1073/pnas.0903616106.

Takahashi, D. Y., Narayanan, D. Z., \& Ghazanfar, A. A. (2013). Coupled oscillator dynamics of vocal turn-taking in monkeys. Current Biology, 23, 2162-2168.

Tobias, M. L., Barnard, C., O'Hagan, R., Horng, S. H., Rand, M., \& Kelley, D. B. (2004). Vocal communication between male Xenopus laevis. Animal Behaviour, 67 353-365.

Van Dyk, D. A., Taylor, A. J., \& Evans, C. S. (2007). Assessment of repeated displays: a test of possible mechanisms. Journal of Experimental Biology, 210(17), 3027-3035. http://dx.doi.org/10.1242/jeb.007492.

Versace, E. Endress, A. D. \& Hauser, M. D. (2008). Pattern recognition mediates flexible timing of vocalizations in nonhuman primates: experiments with cottontop tamarins. Animal Behaviour, 76, 1885-1892.

\section{Appendix}

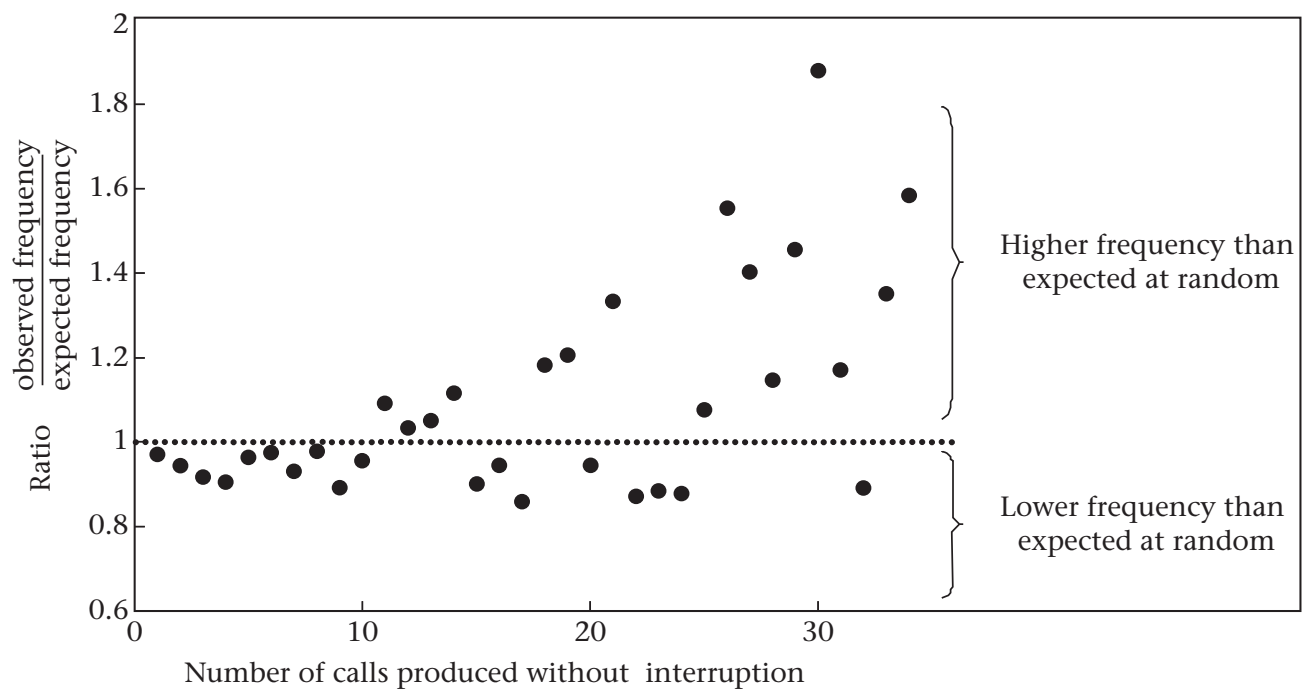

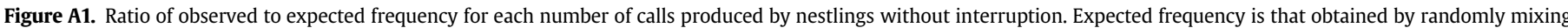

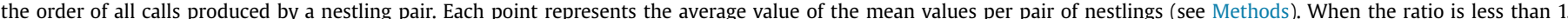

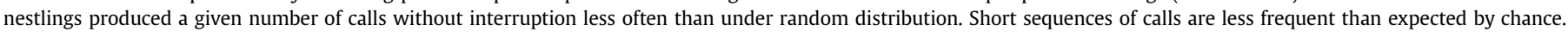


(a)

Solo

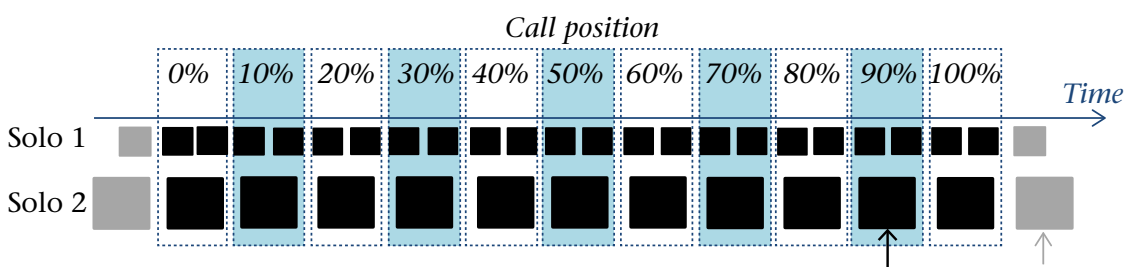

owlet call opponent call

(b)

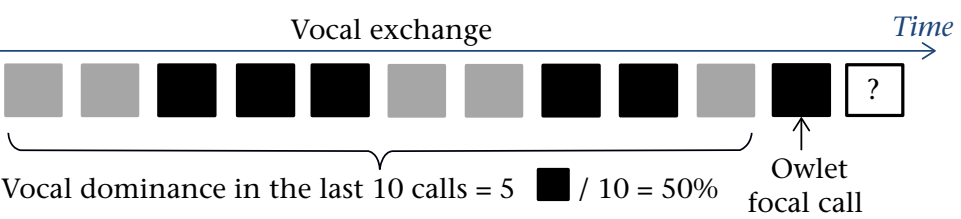

(c)

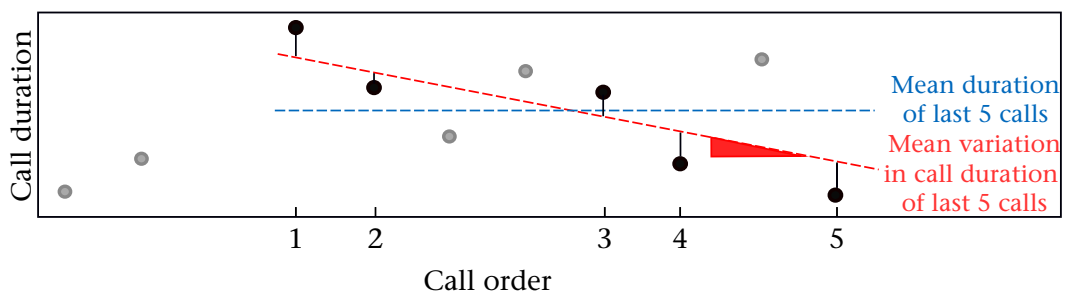

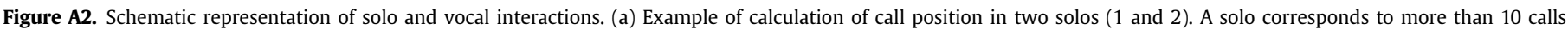

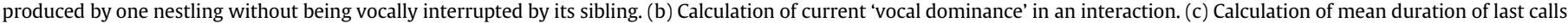
produced by the focal nestling and of the variation of call duration in the last calls against call position.

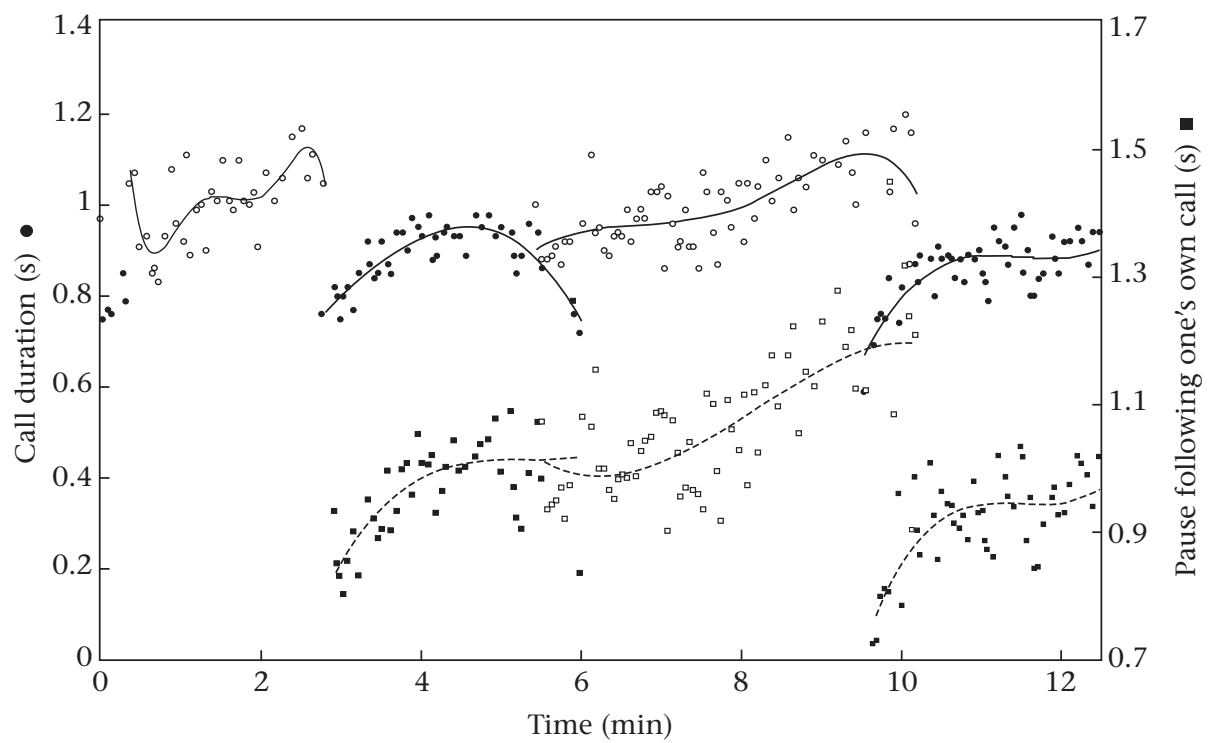

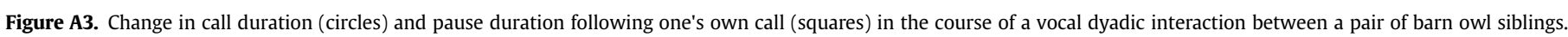

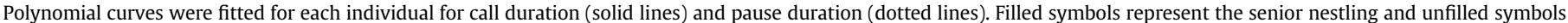
the junior sibling. Each point represents a call. 
- Senior food-deprived • Senior food-satiated $\circ$ Junior food-deprived $\circ$ Junior food-satiated • Playback
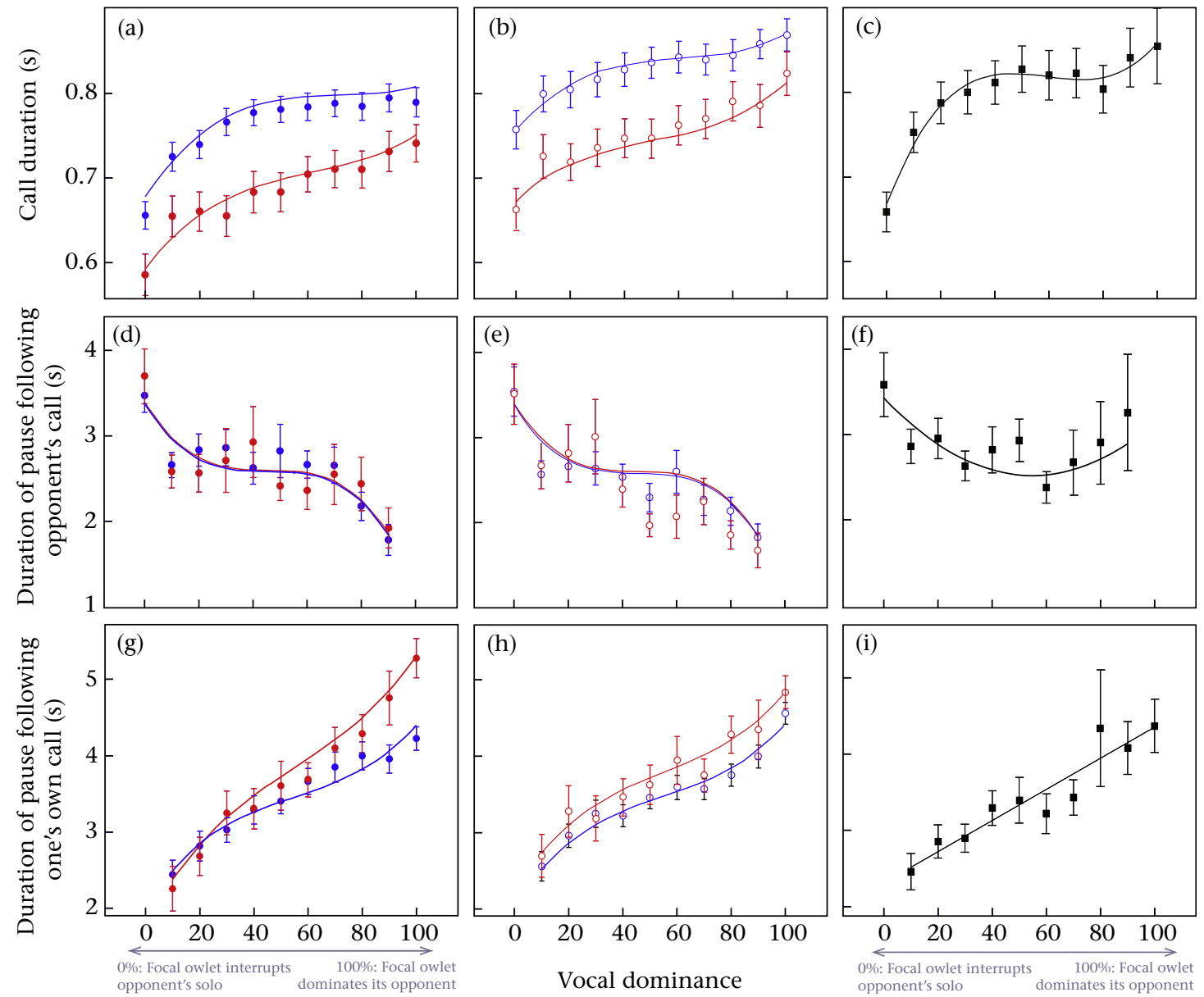

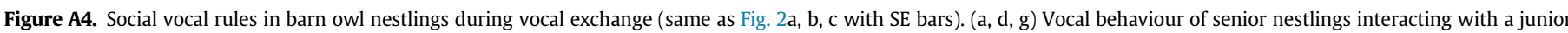

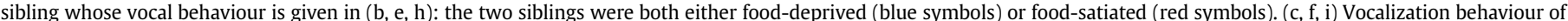

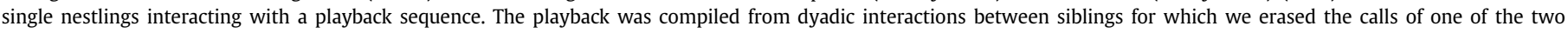

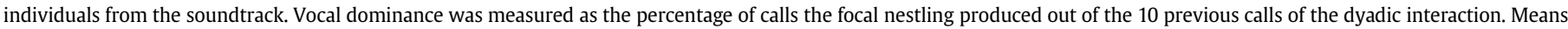
are given $\pm \mathrm{SE}$. 
- Senior food-deprived • Senior food-satiated $\circ$ Junior food-deprived $\circ$ Junior food-satiated • Playback

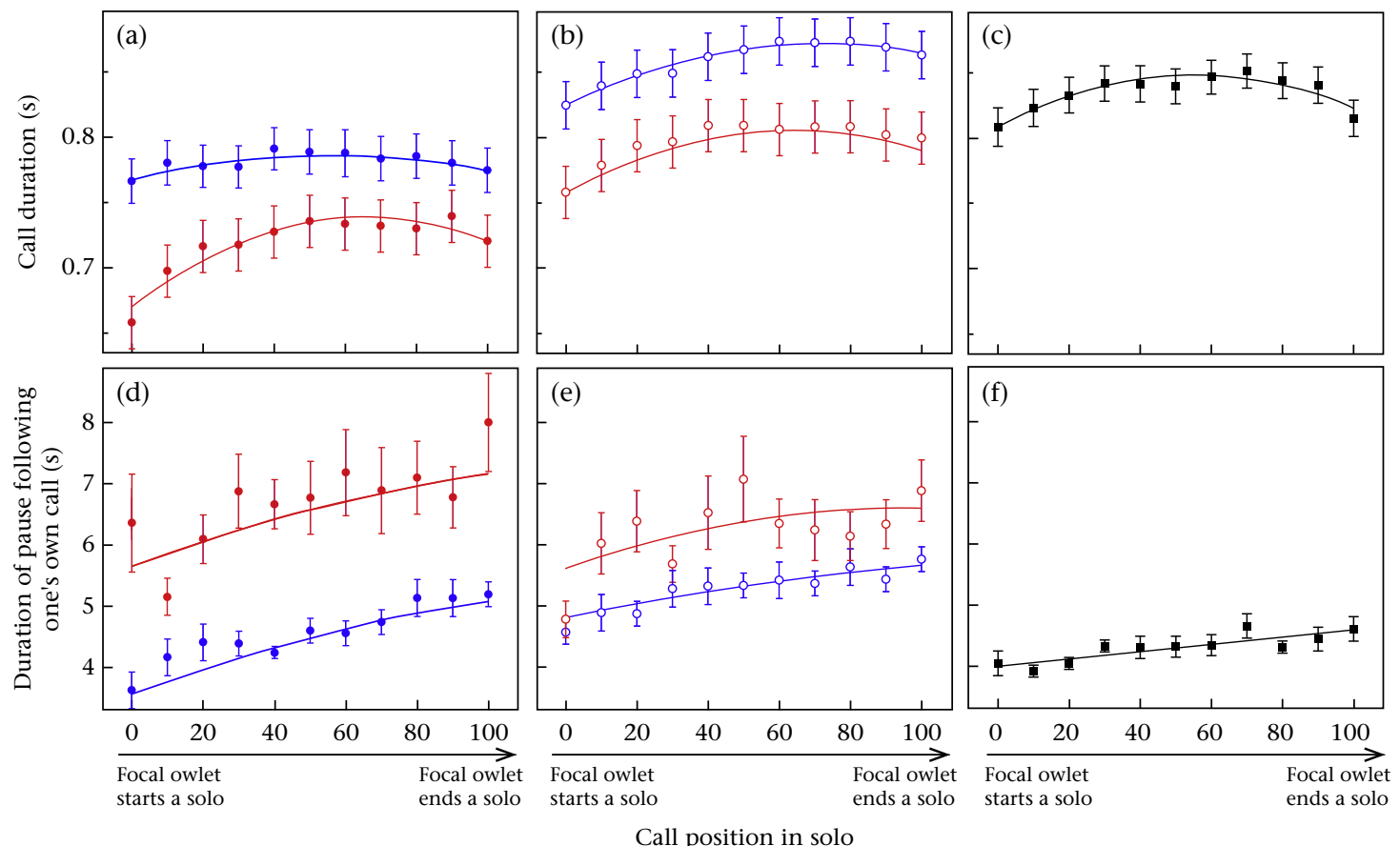

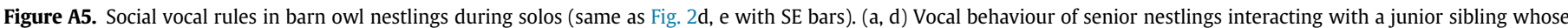

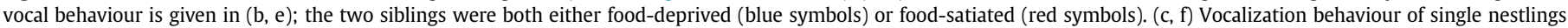

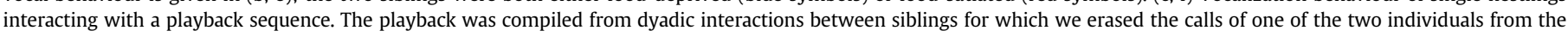
soundtrack. Call position was measured as the percentage of calls previously produced compared to the total solo length. Means are given \pm SE. 